\title{
Programação tangível e construção de significado: criação de símbolos para o ambiente TaPrEC junto com professoras de ensino fundamental
}

\author{
Marleny Luque Carbajal ${ }^{1}$, M. Cecília C. Baranauskas ${ }^{1}$ \\ ${ }^{1}$ Instituto de Computação - Universidade Estadual de Campinas (UNICAMP) \\ Caixa Postal 6.176 - 13.083 - 970 - Campinas - SP - Brasil \\ marleny.carbajal@students.ic.unicamp.br, cecilia@ic.unicamp.br
}

\begin{abstract}
Participatory Design is an approach that is characterized by the active participation of users as part of the design team, thus reflecting in the design product their perspectives and needs. BrainDraw is a participatory technique for use in the design phase. From this context, this article aims to report and discuss results of the use of the BrainDraw technique with elementary school teachers, aiming at the design of the programming blocks of TaPrEC, a tangible programming environment for children. The results reinforce the importance of teachers' participation in the design of educational computing environments for their use.
\end{abstract}

Resumo. O Design Participativo é uma abordagem que se caracteriza pela participação ativa dos usuários como parte da equipe de design, refletindo assim no produto de design suas perspectivas e necessidades. O BrainDraw é uma técnica participativa para uso na fase de design propriamente dita. Este artigo objetiva relatar e discutir as experiências e os resultados obtidos durante a aplicação da técnica BrainDraw com professoras de ensino fundamental no contexto de design dos blocos de programação do ambiente TaPrEC de programação tangível. Os resultados reforçam a importância da participação de professores no design de ambientes computacionais educacionais para seu uso.

\section{Introdução}

As pesquisas de Bruner [1966] sobre o desenvolvimento cognitivo revelam três etapas de processamento e representação de informações: manuseio e ação, organização perceptiva e imagens, e utilização de símbolos. Essas etapas são parte de um sistema de três camadas de representações internas: i) enativa (baseado na ação), ii) icônica (com base na imagem), e iii) simbólica (com base na linguagem). A terceira camada, a representação simbólica, constitui a forma mais elaborada de representação; a pessoa representa a informação com base em símbolos, ideias, pensamentos e conceitos. A relação entre as três camadas de representações internas (enativa, icônica e simbólica) do desenvolvimento cognitivo é muito importante para o aprendizado do sujeito.

Neste artigo discutimos resultados de nossa experiência na criação de símbolos para a linguagem de programação tangível do ambiente TaPrEC [Carbajal \& Baranauskas 2015] e como esses símbolos contribuíram para o entendimento e aprendizado desse ambiente. Em 2015, realizamos um Estudo de Caso para avaliar o 
VII Congresso Brasileiro de Informática na Educação (CBIE 2018)

Anais do XXIV Workshop de Informática na Escola (WIE 2018)

ambiente TaPrEC no qual participaram professoras e alunos de ensino fundamental. Nesse estudo verificamos que os participantes aprenderam conceitos básicos de programação e a lógica para construir um programa tangível. No entanto, observamos que os símbolos utilizados nos objetos tangíveis (propostos pela criadora de TaPrEC) dificultavam o entendimento dos conceitos de programação; por exemplo, os participantes confundiam o bloco "fim da repetição" (Figura 3b) com o bloco "fim" utilizado para finalizar o programa (Figura 2a), devido ao fato que ambos os símbolos eram representados por uma forma circular. Uma das sugestões que recebemos dos professores para aprimorar nosso ambiente foi "melhorar os desenhos dos blocos de programação para facilitar a interpretação". Para os professores, os símbolos de alguns blocos de programação não comunicavam uma informação clara sobre a funcionalidade dos mesmos. Para resolver esse problema, decidimos envolver os professores no redesign dos símbolos dos blocos de programação do ambiente TaPrEC.

Na área de Interação Humano-Computador (IHC) se praticam diferentes técnicas para envolver o usuário no processo de criação de artefatos computacionais para seu uso. O Design Participativo (DP) [Muller et. al 1997, Schuler \& Namioka 1993] apresenta-se como um método de investigação em que o designer oferece técnicas para viabilizar a participação de usuários prospectivos na proposição de soluções que atendam às suas necessidades. No DP, os usuários de tecnologia não são apenas fontes de informação ou sujeitos de observação; eles têm a capacidade de contribuir efetivamente no processo de design e desenvolvimento de sistemas computacionais. Alguns autores que utilizaram o DP no design de ambientes computacionais são: i) Melo et. al (2008) visando obter representações de um grupo de crianças para criar um espaço infantil na internet; ii) Matsunaga et. al (2012) para envolver crianças com hemofilia para a construção de um jogo educativo. Na nossa revisão de literatura, não achamos evidências da utilização do DP no design de ambientes computacionais tangíveis.

Considerando o que foi exposto, este trabalho objetivou o redesign de símbolos para os blocos de repetição do ambiente de programação tangível para crianças TaPrEC envolvendo as principais partes interessadas, de modo que os símbolos criados fizessem sentido para elas e fossem adequados a suas necessidades e a seu contexto. Para alcançar nosso objetivo aplicamos a técnica participativa BrainDraw com um grupo de professoras de ensino fundamental no contexto do Estudo de Caso realizado num espaço educativo que oferece atividades no contraturno da escola. Assim, este artigo está organizado da seguinte forma: na seção 2 realizamos uma breve descrição do ambiente TaPrEC; na seção 3 apresentamos o referencial teórico-metodológico que adotamos neste trabalho; a partir desse referencial, na seção 4 detalhamos as atividades realizadas com professoras e alunos de ensino fundamental durante processo de redesign dos símbolos para o ambiente TaPrEC; na seção 5, fazemos a discussão relativa aos resultados obtidos e finalmente na seção 6 apresentamos as considerações finais.

\section{O ambiente de programação tangível TaPrEC}

TaPrEC (acrônimo de Tangible Programming Environment for Children) é um ambiente de programação tangível de baixo custo desenvolvido para ensinar conceitos básicos de programação (sequência, repetição e procedimento). $\mathrm{O}$ ambiente permite criar programas de computador tangíveis organizando blocos de madeira equipados com etiquetas de Identificação por Radiofrequência (RFID-Radio-Frequency IDentification). 
VII Congresso Brasileiro de Informática na Educação (CBIE 2018)

Anais do XXIV Workshop de Informática na Escola (WIE 2018)

A execução do programa tangível é feita no contexto do ambiente de programação Scratch. Na Figura 1a mostramos os componentes do ambiente TaPrEC: o hardware de baixo custo, o software de controle e os blocos de programação.

a)

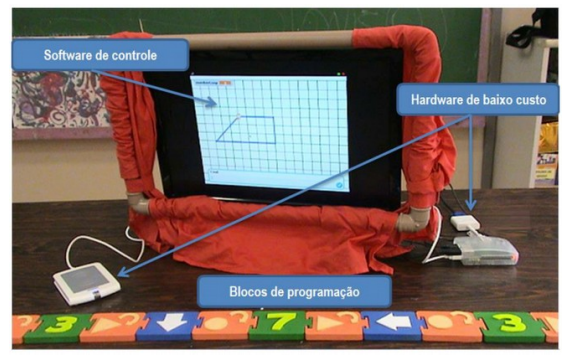

b)

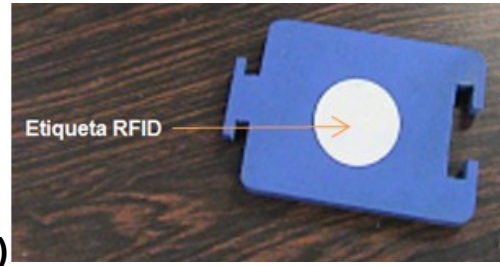

Figura 1. a) componentes do ambiente TaPrEC; b) etiqueta RFID incorporada no bloco de programação.

Os blocos de programação são blocos coloridos de madeira semelhantes a peças de quebra-cabeças que contém uma etiqueta RFID (Figura 1b) e um símbolo em altorelevo para representar sua funcionalidade. Como ilustramos na Figura 2, TaPrEC possui diferentes tipos de blocos de programação agrupados de acordo a sua funcionalidade e com uma cor característica.

a)

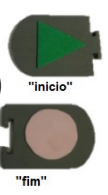

b)

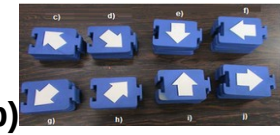

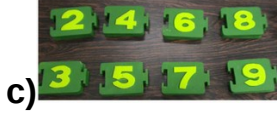

d)

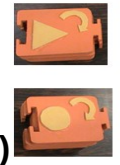

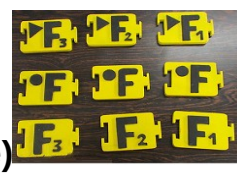

Figura 2. Tipos de blocos de programação: a) controle (bloco "inicio" e bloco "fim"); b) deslocamento; c) números; d) repetição; e) procedimentos.

Na Figura 3c à esquerda, mostramos um exemplo de um programa tangível que utiliza uma estrutura repetitiva. Como observamos, para criar o programa tangível primeiro colocamos o bloco "inicio" seguido de um bloco de número para indicar o número de repetições, depois colocamos o bloco "inicio da repetição" (Figura 3a) seguido dos blocos que serão repetidos (por exemplo: blocos de deslocamento), colocamos o bloco "fim da repetição" (Figura 3b) e finalmente o bloco “fim”. Quando o usuário passa o leitor RFID pelos blocos de programação, os identificadores das etiquetas RFID são enviados ao software de controle para ser processados e o resultado é mostrado no ambiente de programação Scratch (Figura 3c à direita). O exemplo indica que o personagem da direita repetirá três vezes as seguintes ações: dois movimentos "para frente” e um movimento "para cima”.

a)

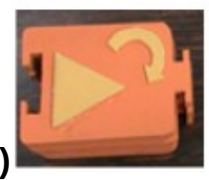

b)

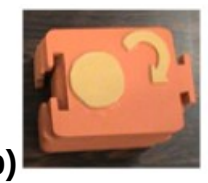

c)

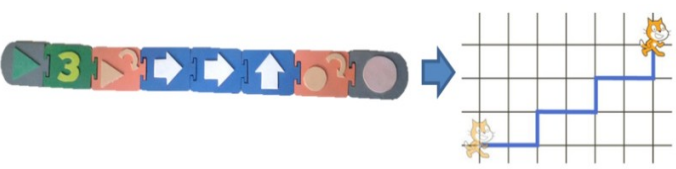

Figura 3. a) bloco "inicio da repetição"; b) bloco "fim da repetição"; c) exemplo de um programa tangível com uma estrutura repetitiva.

\section{Referencial Teórico-Metodológico}

Nesta seção apresentamos o Design Participativo e a técnica BrainDraw, assim como o formulário da autoavaliação de emoções utilizado nas atividades participativas. 
VII Congresso Brasileiro de Informática na Educação (CBIE 2018)

Anais do XXIV Workshop de Informática na Escola (WIE 2018)

\subsection{Design Participativo}

O DP propõe a participação do usuário final, de forma ativa, nas várias etapas de desenvolvimento de tecnologias [Muller et. al 1997]. Entre seus benefícios estão as decisões democráticas, o compartilhamento de experiências e de conhecimentos entre as diferentes partes interessadas, assim como a aceitação do produto construído de forma colaborativa [Mombach et. al 2010]. O DP é conduzido com métodos e práticas a serem realizadas com o usuário, aplicadas em diferentes fases de desenvolvimento. A técnica participativa BrainDraw, utilizada na fase de design, caracteriza-se por um brainstorming cíclico e gráfico no qual cada participante faz um desenho inicial em uma folha de papel e, transcorrido um intervalo de tempo, passa seu desenho para o colega, que continua o desenho encontrado na folha. O processo continua rodando até que todos tenham colaborado na criação de cada um dos outros participantes. Como resultado geram-se várias propostas à interface do sistema que podem ser consolidadas pelo grupo em uma única versão.

\subsection{Autoavaliação de emoções}

As escalas da autoavaliação de emoções (SAM-Self-Assessment Manikin) [Bradley \& Lang 1994] apresentam vários bonecos ao longo de três dimensões afetivas (Figura 4). $\mathrm{Na}$ dimensão de satisfação (primeira linha), a escala varia de um boneco feliz e sorridente a um boneco triste. Na dimensão de motivação (segunda linha), varia de uma figura animada com os olhos abertos até uma figura sonolenta. A dimensão de controle (terceira linha) representa o domínio sobre o objeto ou situação e está propositalmente apresentada na ordem inversa das dimensões anteriores, isto é do menor controle da situação ao maior controle. Cada dimensão afetiva tem uma escala de 9 pontos representados por círculos. Neste trabalho analisamos os resultados da autoavaliação de emoções da seguinte maneira: os valores mais altos (9, 8 e 7) representam uma resposta afetiva positiva; os valores intermediários (6, 5 e 4) representam uma resposta afetiva neutra; e os valores mais baixos (3, 2 e 1) representam uma resposta afetiva negativa.

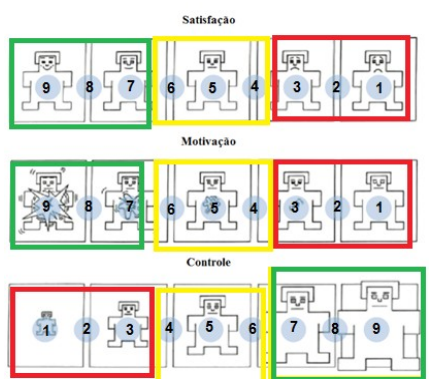

Figura 4. Formulário da autoavaliação de emoções

\section{Um estudo sobre o redesign de símbolos para o ambiente TaPrEC}

As atividades apresentadas nas seguintes subseções dizem respeito à atuação de professoras de ensino fundamental no redesign de símbolos para os blocos de repetição do ambiente TaPrEC; e a experimentação e avaliação desses símbolos, realizado por alunos e professoras de ensino fundamental, no contexto do Estudo de Caso num espaço educacional real.

\subsection{Cenário e participantes}


VII Congresso Brasileiro de Informática na Educação (CBIE 2018)

Anais do XXIV Workshop de Informática na Escola (WIE 2018)

O Estudo de Caso teve lugar no Programa de Integração e Desenvolvimento da Criança e do Adolescente (PRODECAD) que oferece educação suplementar a crianças de 6 a 14 anos matriculadas na EEPG "Sergio Pereira Porto" que funciona dentro do campus da Universidade Estadual de Campinas (UNICAMP), São Paulo. As atividades foram agendadas formalmente pela coordenação como parte das "Oficinas de Interfaces Computacionais" que têm sido conduzidas semestralmente por pesquisadores da área de IHC desde o ano 2015. Participaram das oficinas: sete professoras de ensino fundamental (entre 33 e 52 anos) e um total de doze alunos (entre 7 e 10 anos).

\subsection{Oficinas}

No primeiro semestre de 2017, agendamos três oficinas com uma duração de 60 minutos cada para realizar as atividades participativas. Ao finalizar cada oficina os participantes preenchiam o formulário da autoavaliação de emoções. A seguir apresentamos em detalhe as atividades desenvolvidas em cada oficina.

\section{Oficina 1: BrainDraw}

Trabalhamos com sete professoras que participaram das "Oficinas de Interfaces Computacionais" durante o primeiro semestre de 2015 e tiveram contato com a primeira versão do ambiente TaPrEC [Carbajal \& Baranauskas 2015]. Naquele semestre, as professoras colaboraram dando sugestões que nos permitiram aprimorar o ambiente. $\mathrm{Na}$ Figura 5 mostramos os blocos de repetição da primeira versão de TaPrEC que eram representadas pelas palavras “INICIO REPETIR" e "FIM REPETIR".

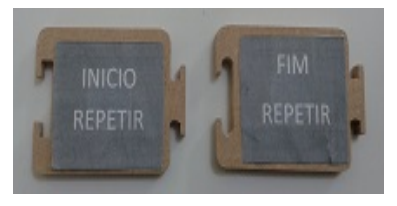

Figura 5. Blocos de repetição da primeira versão de TaPrEC

Buscando identificar quanto as professoras lembravam-se do funcionamento do ambiente TaPrEC, a pesquisadora colocou na mesa de trabalho os blocos da primeira versão e perguntou: “Alguém pode explicar como funcionam os blocos de repetição?”. Uma professora respondeu: "Por exemplo, se você quer ir reto cinco vezes, primeiro coloca o início (pegando o bloco INICIO REPETIR), depois deve colocar o bloco da ação (pegando um bloco de deslocamento) e depois colocar este bloco (pegando o bloco FIM REPETIR)”. Quase todas as professoras concordaram com a explicação da sua colega. Observamos que as professoras lembravam parcialmente como utilizar os blocos de repetição já que não utilizaram o bloco de número para indicar o número de repetições. Imediatamente a pesquisadora explicou o funcionamento dos blocos de repetição e, uma vez solucionadas as dúvidas das professoras, passou explicar o objetivo da oficina: criar símbolos para os blocos de repetição que fossem fáceis de identificar por qualquer aluno ou professora. A pesquisadora explicou também a dinâmica da técnica participativa BrainDraw.

Após essa primeira etapa, as professoras formaram duas equipes. Em cada equipe participou um pesquisador da área de IHC. Iniciamos o BrainDraw realizando rodadas de 1 minuto. Observamos que a primeira rodada resultou difícil para algumas professoras porque não conseguiram desenhar nada. A partir da segunda rodada as ideias e desenhos fluíram naturalmente. Uma vez finalizadas as rodadas, cada equipe realizou a discussão e consolidação dos símbolos criados (Figuras 6a e 7a), de modo que 
VII Congresso Brasileiro de Informática na Educação (CBIE 2018)

Anais do XXIV Workshop de Informática na Escola (WIE 2018)

resultasse um único símbolo para o bloco "inicio da repetição" e outro para o bloco "fim da repetição". Finalmente, uma representante de cada equipe explicou para todos os participantes da oficina como chegaram aos símbolos finais (Figuras 6b e 7b) e o significado dos mesmos. O relato oral transcrito a seguir revela como as professoras de cada equipe representaram a funcionalidade dos blocos de repetição.

Professora equipe 1: "Início repetir é o símbolo de vezes $X$, porque a criança sabe que vezes representa repetir. Para parar a repetição utilizamos a mãozinha em sinal de pare. Usamos a cor vermelho porque no sinal de trânsito vermelho indica pare e a cor verde indica vai”.

a)

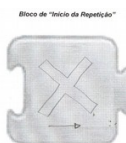

(1)

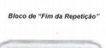

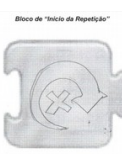

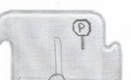

.
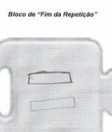
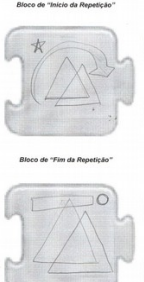
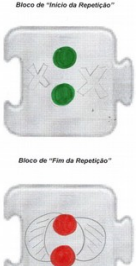

b)

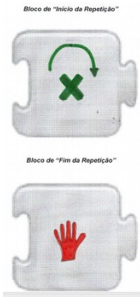

Figura 6. BrainDraw equipe 1: a) símbolos criados em cada rodada; b) símbolos finais.

Professora equipe 2: "A gente utilizou o verde para continuar e o vermelho para parar. A gente pensou na multiplicação e indica as vezes que qualquer número vai repetir. $O$ triângulo simboliza a continuidade. Para finalizar a repetição utilizamos o ponto, que é um ponto final daquele momento".

a)

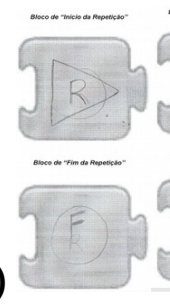

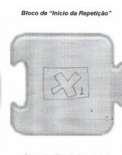

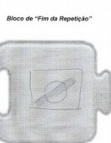

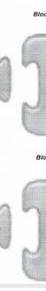
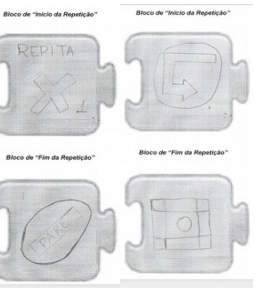

b)

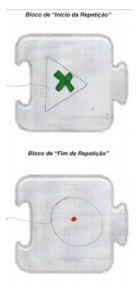

Figura 7. BrainDraw equipe 2: a) símbolos criados nas rodadas; b) símbolos finais.

Para finalizar a oficina, as participantes preencheram a autoavaliação de emoções para que avaliassem sua resposta afetiva com relação à técnica BrainDraw. Os resultados da autoavaliação de emoções (Figura 8) mostram que as respostas se concentram no ponto 5 da escala, então podemos afirmar que a maior parte das professoras teve uma resposta afetiva neutra para as três dimensões afetivas.

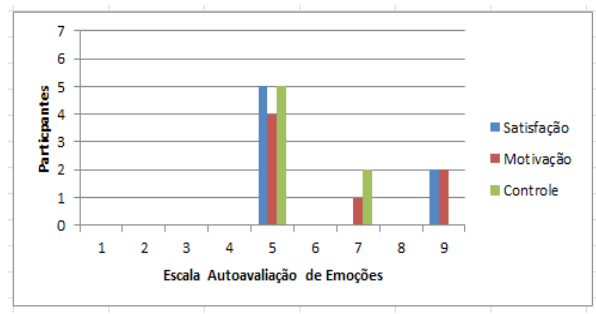

Figura 8. Resultados da autoavaliação de emoções - Oficina 1 - BrainDraw

\section{Oficina 2: Experimentação e avaliação das professoras}

Nesta oficina as professoras criaram programas tangíveis utilizando dois tipos de blocos de repetição: i) os novos blocos que utilizavam os símbolos criados pela equipe 1 (Figura 9a); e ii) a proposta da criadora de TaPrEC (Figuras 3a e 3b). Propomos um 
VII Congresso Brasileiro de Informática na Educação (CBIE 2018)

Anais do XXIV Workshop de Informática na Escola (WIE 2018)

exercício que consistia em movimentar um personagem desde uma posição inicial até a posição de outro personagem. Como mostramos na Figura 9b, enquanto o personagem se movimentava seu caminho era marcado.
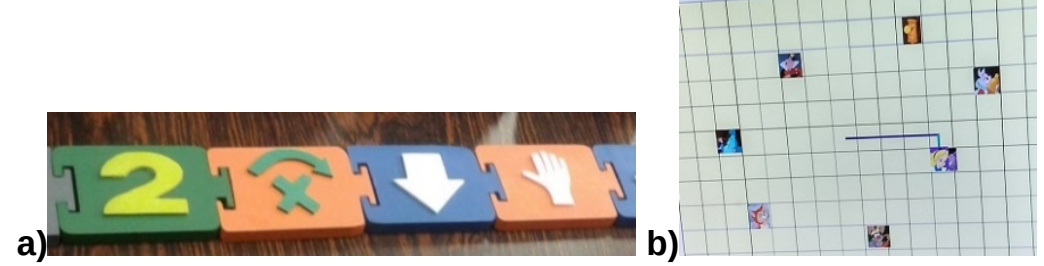

Figura 9. Oficina 2: a) novos blocos de repetição; b) exercício proposto.

As professoras trabalharam em duas equipes e planejaram em papel seus programas tangíveis (Figura 10a). No momento de montar os programas tangíveis (Figura 10b), a equipe 1 utilizou os novos blocos de repetição; e a equipe 2 utilizou a proposta da pesquisadora. Depois cada equipe passou o leitor RFID pelo programa tangível e observaram o resultado no ambiente Scratch (Figura 10c).
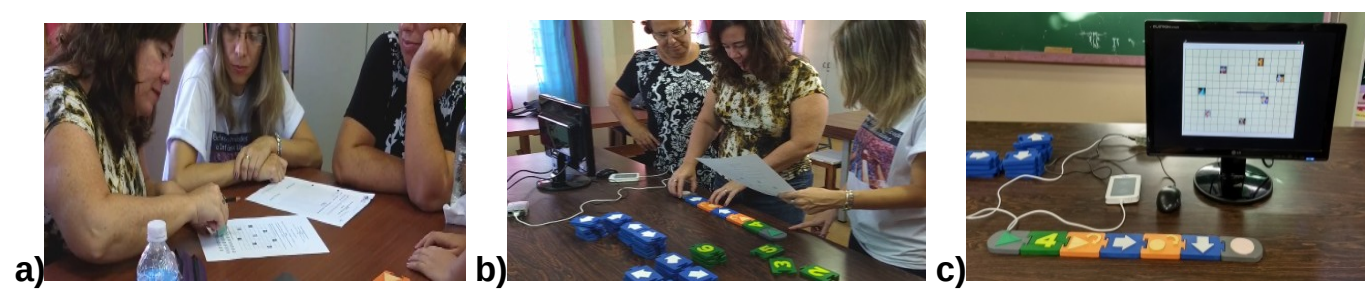

Figura 10. Oficina 2: a) planejamento da solução ao exercício; b) montagem do programa tangível; c) resultado da execução do programa tangível.

Observamos que a equipe 2 tinha algumas dificuldades para identificar a funcionalidade dos blocos de programação e corrigiu duas vezes seu programa tangível. Apesar disso, ambas as equipes conseguiram completar o exercício corretamente. Após a etapa de experimentação, as professoras foram consultadas sobre qual proposta segundo sua opinião representava melhor o conceito de "repetição" e era mais fácil de entender. Uma professora comentou que achava que o ambiente tinha "muitos símbolos para a criança decorar". Outra professora falou que a proposta da pesquisadora tinha "muita semelhança" com os blocos de controle, sugerindo que isso causa confusão entre esses dois tipos de blocos. Para outra professora as duas propostas "podiam dar certo", mas "pensando nas crianças" a proposta da "mãozinha” era mais atraente e fácil de entender. No entanto, uma professora tinha problemas com essa proposta já que "a meia flecha acima da X”, passava para ela a ideia de "meio caminho" ou alguma ação incompleta, e não a ideia de repetição. Essa mesma professora sugeriu utilizar os "parênteses da multiplicação" como símbolos dos blocos de repetição. As professoras concordaram que os parênteses seriam uma ótima representação para os blocos de repetição porque as crianças já estavam familiarizadas com esses símbolos.

Uma vez que as professoras expressaram suas opiniões, preencheram o formulário de autoavaliação de emoções. Os resultados da autoavaliação de emoções (Figura 11) mostram que com relação às dimensões de satisfação e motivação, a maior parte das professoras teve uma resposta afetiva positiva. E com relação à dimensão de controle, as respostas se concentram no ponto 5 da escala, então a maioria das professoras teve uma resposta afetiva neutra para esta dimensão afetiva. 
VII Congresso Brasileiro de Informática na Educação (CBIE 2018)

Anais do XXIV Workshop de Informática na Escola (WIE 2018)

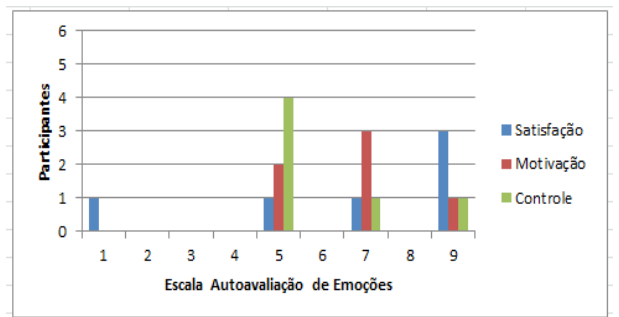

Figura 11. Resultados da autoavaliação de emoções - Oficina 2 - professoras

\section{Oficina 3: Experimentação e avaliação dos alunos}

Participaram da terceira oficina doze alunos que já tinham experimentado o ambiente TaPrEC num outro encontro, então estavam familiarizadas com a programação tangível. Inspirados numa cena da história da "Alice no País das Maravilhas" onde o personagem do Coelho repetia a frase "é tarde, é tarde", o exercício proposto para esta oficina foi criar um programa tangível para que o personagem repetisse várias vezes essa frase (Figura 13a). Para isto disponibilizamos um bloco de programação especial que estava associado a um arquivo mp4 com a frase "e tarde". Os alunos formaram duas equipes: a equipe 1 utilizou a proposta da pesquisadora para os blocos de repetição, e a equipe 2, a proposta das professoras. As equipes planejaram o programa tangível em papel (Figura 12a), depois criaram seus programas tangíveis, passaram o leitor RFID (Figura 12b) e observaram o resultado no ambiente Scratch (Figura 12c).

a)
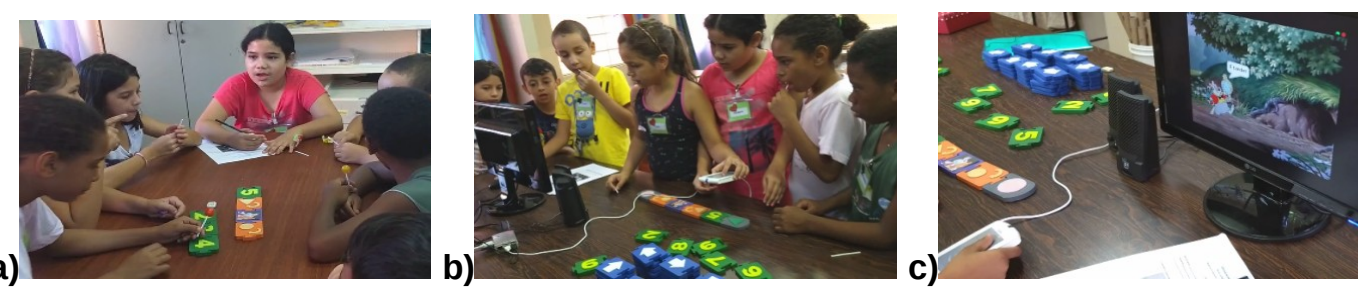

Figura 12. Oficina 3: a) alunos planejando o programa tangível; b) alunos montando o programa tangível; c) resultado mostrado no ambiente Scratch.

Na primeira tentativa, a equipe 1 utilizou dois blocos de número no seu programa tangível. A pesquisadora explicou que o TaPrEC aceita apenas um bloco de número na estrutura repetitiva. Após a explicação, conseguiram montar o programa tangível corretamente. A equipe 2 precisou ajuda da pesquisadora para lembrar como montar uma estrutura repetitiva e conseguiram montaram seu programa tangível corretamente na primeira tentativa. Para verificar se os alunos entenderam realmente o funcionamento dos blocos de repetição, realizamos uma avaliação individual que consistia numa folha de papel onde cada criança devia explicar o significado de cada bloco do programa tangível criado pelo seu grupo. Na Figura 13b mostramos dois exemplos de respostas dos alunos ao exercício de avaliação. Ao revisar as respostas individuais dos doze alunos encontramos que: i) dos seis alunos que utilizaram os blocos de repetição das professoras, quatro conseguiram descrever corretamente a função de cada bloco do seu programa tangível; e dois responderam parcialmente correto, isto é, descreveram corretamente alguns blocos de programação; ii) dos seis alunos que utilizaram a proposta da pesquisadora, dois alunos responderam parcialmente correto; e quatro não conseguiram descrever os blocos de programação, mas indicaram o resultado da execução do programa, por exemplo escreveram "para mover o coelho". Como observamos, os alunos que responderam corretamente a avaliação individual eram parte da equipe que utilizou os símbolos criados pelas professoras; vários alunos que 
VII Congresso Brasileiro de Informática na Educação (CBIE 2018)

Anais do XXIV Workshop de Informática na Escola (WIE 2018)

utilizaram a proposta da pesquisadora erraram no momento de explicar a funcionalidade dos blocos de programação. Para finalizar a oficina, as crianças preencheram a autoavaliação de emoções.

a)

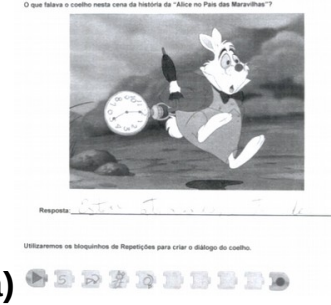

b)

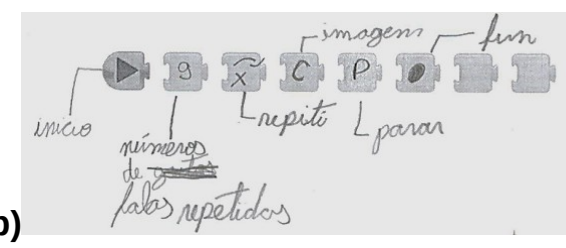

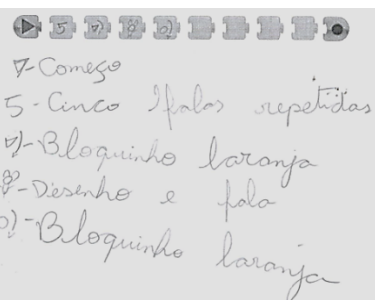

Figura 13. Oficina 3: a) exercício proposto; b) respostas da avaliação individual .

Observamos nos resultados da autoavaliação de emoções dos alunos (Figura 14) que as barras mais altas se concentram no ponto 9 da escala, isto significa que tiveram uma resposta afetiva bastante positiva nas três dimensões afetivas, para a oficina, independentemente da equipe.

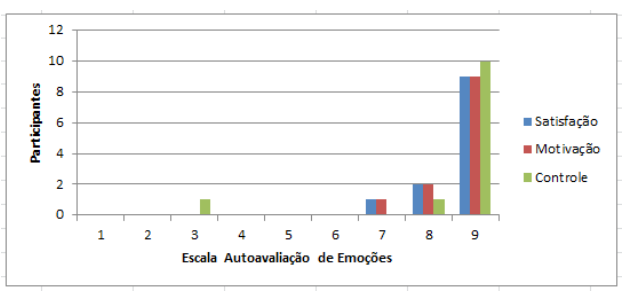

Figura 14. Resultados da autoavaliação de emoções - Oficina 3 - alunos

\section{Discussão}

Os resultados das oficinas, conforme apresentados na seção anterior, destacam que os símbolos criados pelas professoras tiveram uma melhor aceitação por parte de professoras e crianças, refletida também no uso que as crianças fizeram em seu programa tangível. Esta aceitação positiva pode decorrer do fato que as soluções participativas propostas pelas professoras sugerem associações com elementos cotidianos, tais como os sinais de trânsito e o símbolo da multiplicação, para representar o número de repetições com o 'vezes' $(\mathrm{x})$ de 'repetir um número de vezes'. A proposta das professoras de redesign dos blocos de repetição fez uso do caráter icônico (e metafórico) da representação. As equipes de trabalho conseguiram planejar e executar corretamente suas soluções tangíveis para as atividades propostas. No entanto, os seis alunos que trabalharam com os blocos de repetição propostos pela pesquisadora não conseguiram ou tiveram dificuldades em explicar corretamente seu programa tangível, sugerindo, assim, que a representação simbólica (os símbolos abstratos na proposta da pesquisadora) desses blocos não facilitavam sua interpretação da linguagem dos blocos do programa tangível, para representar o conceito de repetição. É possível que esses alunos tenham se valido também das cores e formas dos blocos para experimentar e montar a solução correta. A resposta afetiva (neutra) das professoras durante o BrainDraw pode ter sido originada pelo tempo curto das rodadas da técnica, o que pode ter ocasionado certa frustração nas participantes que não conseguiram desenhar nada durante as primeiras rodadas. Apesar disso, na segunda oficina, percebemos que as professoras ficaram felizes ao ver os blocos de repetição com os símbolos que elas mesmas criaram e seu uso pelas crianças. Isto se refletiu na resposta afetiva para essa segunda oficina, que foi em maioria positiva para as dimensões de satisfação e 
VII Congresso Brasileiro de Informática na Educação (CBIE 2018)

Anais do XXIV Workshop de Informática na Escola (WIE 2018)

motivação. Em síntese, a proposta de redesign realizado pelas professoras nos blocos de repetição levaram a representação da linguagem dos blocos, do simbólico representado pela solução inicial da pesquisadora, para o icônico, que parece ter feito mais sentido como o resultado de uso pelas crianças sugere. Novos estudos podem ainda ser conduzidos para explorar o aspecto enativo da interação delas com a programação tangível.

\section{Considerações Finais}

É por meio da análise de como as pessoas se apropriam e utilizam os recursos computacionais que são possíveis modificações e melhoras nos produtos da tecnologia; assim conceitos de áreas como a computação podem ser incorporados mais naturalmente. O Design Participativo é um processo que envolve pesquisadores e usuários finais na criação de produtos para seu uso. Este trabalho teve como objetivo estudar diferentes propostas de símbolos para a representação e entendimento dos blocos de repetição do ambiente TaPrEC, com a motivação de promover uma solução que tivesse a participação dos interessados, a fim de encontrar uma solução que fizesse sentido para eles. Utilizamos a técnica participativa BrainDraw como ferramenta para a obtenção de alternativas de design de acordo com o ponto de vista de professoras de ensino fundamental que participam de um projeto conjunto. Foi possível testar e avaliar umas das soluções criadas pelas professoras obtendo resultados positivos na aceitação e entendimento por parte de crianças e professoras. Espera-se ter dado um passo adiante para melhorar nosso ambiente de programação tangível utilizando soluções criadas pelos próprios usuários. Ao mesmo tempo, indicamos novas oportunidades de pesquisa, que investiguem representações enativas para a programação tangível.

\section{Referências}

Bradley, M. M., \& Lang, P. J. (1994). Measuring emotion: the self-assessment manikin and the semantic differential. Journal of behavior therapy and experimental psychiatry, 25(1), 4959.

Bruner, J. S. (1966). Toward a theory of instruction (Vol. 59). Harvard University Press.

Carbajal. M. L. \& Baranauskas, M. C. C. (2015). TaPrEC: Desenvolvendo um ambiente de programação tangível de baixo custo para crianças. In Nuevas Ideas en Informática Educativa TISE. 363-370.

Matsunaga, R. M., Morais, S. N., Rossi, R. A., \& Borges, M. A. (2012, July). Desenvolvimento de um jogo educativo para apoiar o aprendizado de pacientes com Hemofilia. In Anais do Workshop de Desafios da Computação Aplicada à Educação (pp. 110-119).

Melo, A. M., Baranauskas, M. C. C., \& de Matos Soares, S. C. (2008). Design com Crianças: da Prática a um Modelo de Processo. Brazilian Journal of Computers in Education, 16(01).

Mombach, J. G., Melo, A. M., Wernz, M. C. G., de Freitas Saldanha, J., \& Machado, R. (2010, June). Gurizada. net: inclusão digital em perspectiva participativa. In Anais do Workshop de Informática na Escola (Vol. 1, No. 1, pp. 1069-1078).

Muller, M. J., Haslwanter, J. H., \& Dayton, T. (1997). Participatory practices in the software lifecycle. Handbook of human-computer interaction, 2, 255-297.

Schuler, D., \& Namioka, A. (Eds.). (1993). Participatory design: Principles and practices. CRC Press. 